\title{
Tocilizumab May Be a Key in Therapy for Cytokine Release Syndrome in Older Patients With Severe Symptoms of COVID-19
}

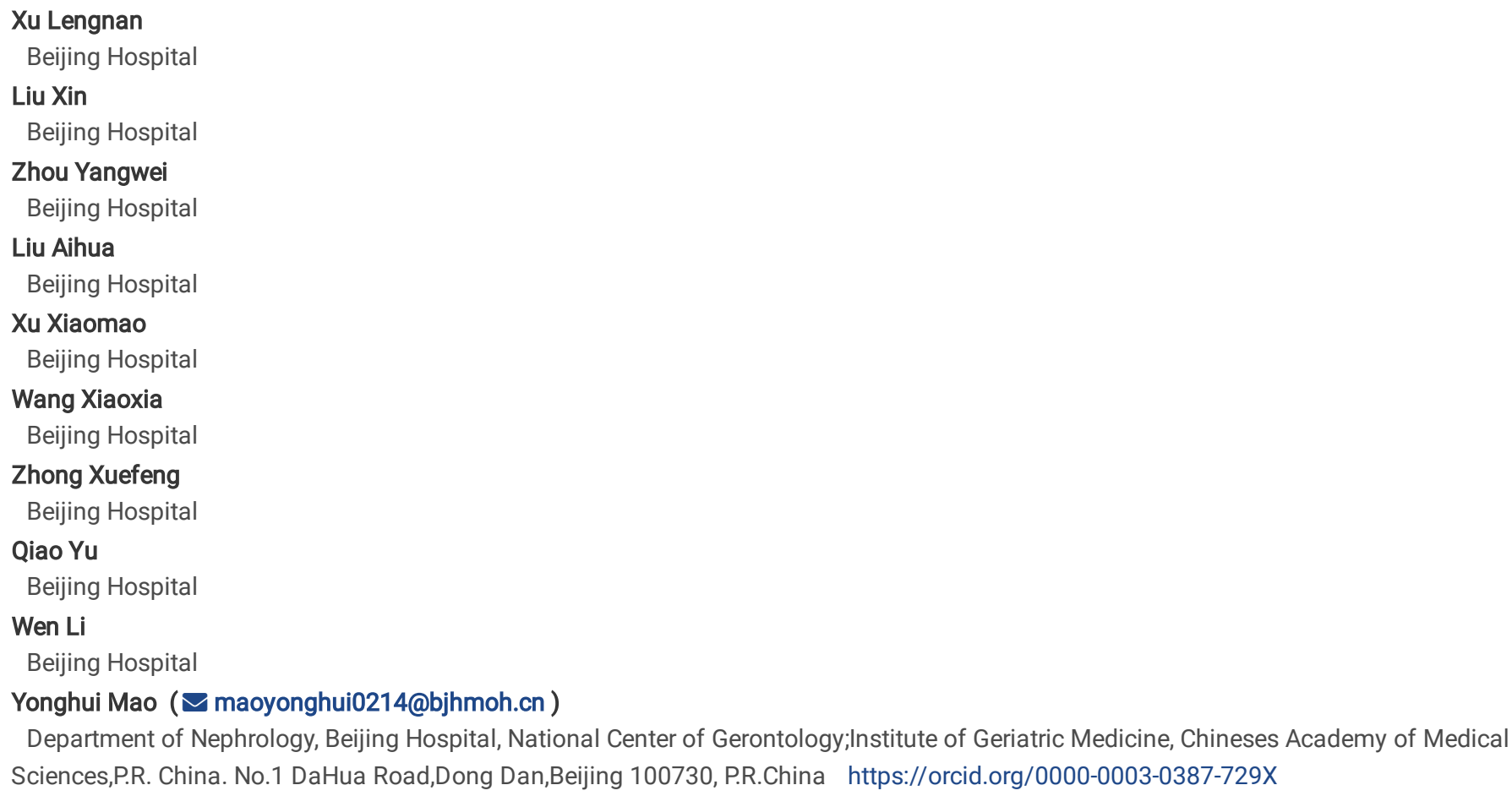

Research article

Keywords: tocilizumab, severe COVID-19, older, cytokine release syndrome, interleukin-6

Posted Date: October 28th, 2020

DOI: https://doi.org/10.21203/rs.3.rs-96809/v1

License: (c) (i) This work is licensed under a Creative Commons Attribution 4.0 International License. Read Full License 


\section{Abstract}

Background Older adults are more susceptible to the novel coronavirus disease 2019 (hereafter, COVID-19) and more likely to develop severe illness. Cytokine release syndrome (CRS) may be an important factor in the development of severe disease in patients with COVID-19. Interleukin-6 (IL-6) is an important cytokine in CRS, and tocilizumab can block the IL- 6 receptor. In this study, we analyzed the therapeutic effects and safety of tocilizumab on CRS in older patients with severe COVID-19.

Methods Between February 10 and March 21, 2020, a total of 19 patients with severe or critical COVID-19 aged $\geq 60$ years met the study inclusion criteria at Tongji hospital in Wuhan city, Hubei Province, China. Patients were divided into two groups: 1 . The tocilizumab group, whose IL-6 levels exceeded the upper limit of normal by > 10-fold; and 2. The no tocilizumab group, with 1L-6 levels < 10-fold the upper normal limit.

Results Patients in the tocilizumab group were older (73.20 \pm 4.44 vs. $66.21 \pm 5.06$ years, $P=0.014)$; had lower lymphocyte counts $(0.71 \pm 0.18$ vs. $1.18 \pm 0.59 \times 10^{9} / \mathrm{L}, \mathrm{P}=0.016$ ); and higher high-sensitivity C-reactive protein (hsCRP) levels $(94.04 \pm 57.24 \mathrm{vs} .51 .65 \pm 45.37 \mathrm{mg} / \mathrm{L}, \mathrm{P}=0.035)$. The increases in ferritin (FER) and hsCRP levels in patients in the tocilizumab group were marked. Except in one patient who died, IL-6, FER, and hsCRP levels, and the neutrophil/lymphocyte ratio, in the remaining four patients decreased following treatment with tocilizumab. Further, patient computerized tomography scan results improved after 3-8 days of tocilizumab treatment. Tocilizumab did not cause any serious adverse reactions. There were no differences in mortality or days until lung computerized tomography improvement between the two groups. The total mortality rate was $10.53 \%$.

Conclusions Our results support the therapeutic efficacy and safety of tocilizumab on older patients with severe COVID-19.

\section{Background}

Older adults are more susceptible to the 2019 novel coronavirus disease, COVID-19. Patients aged $\geq 60$ years account for $15.1-37 \%$ of patients with COVID-19, among which $27.0 \%$ are diagnosed with severe disease $(1,2)$. Compared with younger patients, older adults are more likely to develop severe illness, and have an increased risk of admission to ICU and death(2). Inflammation is the major pathological process in patients with severe COVID-19. The detection of elevated inflammatory cytokines suggests that a cytokine storm, also known as cytokine release syndrome (CRS), may be an important factor in the transition of patients with COVID-19 to severe disease status(3). Blocking the signaling of key cytokines in the inflammatory cytokine storm induced by COVID-19 may reduce the damage to target organs(4). Therefore, the treatment of CRS has become an important part of rescuing patients with severe disease. Interleukin-6 (IL-6) is one such important cytokine(1); levels of which are significantly increased in patients with severe COVID-19, relative to those with non-severe symptoms(5). Tocilizumab is a blocker of the IL-6 receptor (IL-6R), and has potential as an effective drug for treatment of patients with severe COVID-19.

In this study, we enrolled 19 older adult patients with severe COVID-19 whose serum IL-6 levels were significantly increased. Patients with higher levels of IL- 6 were treated with tocilizumab. We analyzed the therapeutic effects on CRS and safety of tocilizumab in older patients with severe COVID-19.

\section{Methods}

\subsection{Patients}

A total of 19 patients who tested positive for COVID-19 by qualitative polymerase-chain-reaction assay met the study inclusion criteria between 10 February and 21 March 2020 in Tongji hospital in Wuhan city, Hubei Province, China. The inclusion criteria were as follows: 1 . Age $\geq 60$ years; 2 . Met the severe or critical criteria, as defined in the "Diagnosis and Treatment Protocol for Novel Coronavirus Pneumonia (7th Interim Edition)" sponsored by the National Health Commission of the People's Republic of China(6); 3 . IL-6 $\geq 7.0 \mathrm{pg} / \mathrm{ml}$; and 4. Rapidly progressed pneumonia, confirmed by imaging examination. The exclusion criteria were: 1. Cancer (solid or hematological tumor); 2 . Autoimmune disease, such as rheumatoid arthritis; 3 . Other infections besides pneumonia, such as urinary tract infection, cellulites, Herpes zoster, gastroenteritis, bacterial arthritis, etc.; or 4 . Other circumstances that the researchers considered inappropriate.

Patients were divided into two groups according to their IL-6 levels: 1. The tocilizumab group, who had IL-6 levels exceeding the upper limit of normal by > 10-fold; and 2. The no tocilizumab group, who had IL-6 levels that did not reach 10-fold the upper limit of normal.

\subsection{Study design and procedures}

This was a retrospective cohort study. All patients received standard treatment in accordance with the relevant guidelines(6), including oxygen therapy, nutrition therapy, antibiotics, antiviral drugs (Abidor, oseltamivir, etc.), glucocorticoids, and Chinese medicine, etc. The dose of tocilizumab was $8 \mathrm{mg} / \mathrm{kg}$ in a single intravenous injection, and a second dose was administered if the patient's symptoms had not improved after $8 \mathrm{~h}$.

All patients underwent the following examinations at admission and regular review: blood routine [white blood cells (WBC), neutrophils (N), and lymphocytes $(\mathrm{L})$, and calculation of $\mathrm{N} / \mathrm{L}$ ratio], high-sensitivity $\mathrm{C}$ reactive protein (hsCRP), erythrocyte sedimentation rate (ESR), ferritin (FER), procalcitonin, and IL-6. A lung computerized tomography (CT) scan was performed on admission and re-checked every 7 days thereafter. Oxygen saturation was measured daily. 


\subsection{Statistical Analysis}

All statistical data were analyzed using Microsoft Excel 2007 and SPSS 22.0. Data conforming to the normal distribution are expressed as mean \pm standard deviation. A t-test was used for comparisons of means between two groups, while the $\chi 2$ test was used for comparisons of rates. $P<0.05$ was considered statistically significant.

\section{Results}

\subsection{Demographic characteristics}

Baseline data from the two patient groups are presented in Table 1. Patients in the tocilizumab group were older $(73.20 \pm 4.44$ vs. $66.21 \pm 5.06$ years, $P$ $=0.014)$; with lower lymphocyte counts $\left(0.71 \pm 0.18 \mathrm{vs} .1 .18 \pm 0.59 \times 10^{9} / \mathrm{L}, \mathrm{P}=0.016\right)$; and higher hsCRP levels $(94.04 \pm 57.24 \mathrm{vs} .51 .65 \pm 45.37 \mathrm{mg} / \mathrm{L}$, $\mathrm{P}=0.035)$. Patients in the tocilizumab group also had higher FER levels; however, the difference was not significant.

Table 1

Baseline data from the two patient groups

\begin{tabular}{|c|c|c|c|c|}
\hline & $\begin{array}{l}\text { No Tocilizumab } \\
(n=14)\end{array}$ & $\begin{array}{l}\text { Tocilizumab } \\
(n=5)\end{array}$ & $t / X^{2}$ & $P$ \\
\hline Age (years) & $66.21 \pm 5.06$ & $73.20 \pm 4.44$ & -2.726 & 0.014 \\
\hline WBC $\left(\times 10^{9} / \mathrm{L}\right)$ & $6.47 \pm 2.55$ & $7.75 \pm 1.30$ & -1.059 & 0.304 \\
\hline$N\left(\times 10^{9} / L\right)$ & $4.57 \pm 2.64$ & $6.61 \pm 1.13$ & -1.650 & 0.117 \\
\hline$L\left(\times 10^{9} / L\right)$ & $1.18 \pm 0.59$ & $0.71 \pm 0.18$ & 2.676 & 0.016 \\
\hline$N / L$ & $5.21 \pm 4.22$ & $9.73 \pm 2.52$ & -2.289 & 0.030 \\
\hline IL-6 (pg/mL) & $23.51 \pm 17.61$ & $139.94 \pm 141.39$ & -3.925 & 0.005 \\
\hline hsCRP (mg/L) & $47.29 \pm 39.43$ & $94.04 \pm 57.24$ & -2.221 & 0.035 \\
\hline FER $(\mu g / L)$ & $1186.26 \pm 1236.26$ & $1803.20 \pm 2031.35$ & -0.794 & 0.439 \\
\hline $\mathrm{ESR}(\mathrm{mm} / \mathrm{h})$ & $51.65 \pm 45.37$ & $94.04 \pm 57.24$ & 0.381 & 0.708 \\
\hline РCT (ng/mL) & $0.12 \pm 0.13$ & $0.19 \pm 0.18$ & -0.972 & 0.344 \\
\hline
\end{tabular}

\subsection{Details of the tocilizumab group}

Patient demographic characteristics before tocilizumab administration are presented in Table 2 . There were 4 males and 1 female in the tocilizumab group. Levels of inflammation indicators, including IL-6, FER, N/L, hsCRP, and ESR, were elevated in all patients. In particular levels of FER and hsCRP were very high; however, procalcitonin levels were almost normal in all subjects. The $\mathrm{SpO}_{2}$ levels of three patients were < $90 \%$, despite receiving oxygen therapy.

Table 2

Clinical manifestations of patients before tocilizumab treatment

\begin{tabular}{|c|c|c|c|c|c|c|c|c|c|c|c|c|c|}
\hline $\begin{array}{l}\text { Patient } \\
\text { No. }\end{array}$ & Sex & $\begin{array}{l}\text { Age } \\
\text { (years) }\end{array}$ & $\begin{array}{l}\text { Days from } \\
\text { onset to } \\
\text { tocilizumab }\end{array}$ & $\begin{array}{l}\text { IL-6 } \\
(\mathrm{pg} / \mathrm{mL})\end{array}$ & $\begin{array}{l}\text { FER } \\
(\mu \mathrm{g} / \mathrm{L})\end{array}$ & $\begin{array}{l}\text { WBC } \\
(\times \\
\left.10^{9} / L\right)\end{array}$ & $\begin{array}{l}\text { NEUT } \\
(\times \\
\left.10^{9} / \mathrm{L}\right)\end{array}$ & $\begin{array}{l}\text { LYMPH } \\
(\times \\
\left.10^{9} / \mathrm{L}\right)\end{array}$ & $\mathrm{N} / \mathrm{L}$ & $\begin{array}{l}\text { hsCRP } \\
(\mathrm{mg} / \mathrm{L})\end{array}$ & $\begin{array}{l}\text { ESR } \\
(\mathrm{mm} / \mathrm{h})\end{array}$ & $\begin{array}{l}\text { PCT } \\
(\mathrm{ng} / \mathrm{mL})\end{array}$ & $\begin{array}{l}\mathrm{SpO}_{2} \\
\text { (\%, } \\
\text { with } \\
\text { oxygen } \\
\text { supply) }\end{array}$ \\
\hline 1 & $M$ & 75 & 13 & 74.24 & 1243.0 & 4.97 & 3.88 & 0.69 & 5.62 & 136.3 & 82 & 0.09 & 98.4 \\
\hline 2 & $M$ & 78 & 45 & 64.50 & 670.5 & 4.59 & 4.19 & 0.31 & 13.52 & 126.8 & 25 & 0.08 & 98.8 \\
\hline 3 & $\mathrm{~F}$ & 66 & 14 & 72.77 & 1109.6 & 7.68 & 6.70 & 0.69 & 9.71 & 49.8 & 25 & 0.07 & 86.5 \\
\hline 4 & M & 74 & 19 & 392.00 & 5380.4 & 6.3 & 5.67 & 0.42 & 13.50 & 100.2 & 72 & 0.50 & 85.1 \\
\hline 5 & $\mathrm{M}$ & 73 & 14 & 133.4 & 768.2 & 6.90 & 5.24 & 0.99 & 5.29 & 91.01 & 56 & 0.10 & 88.0 \\
\hline
\end{tabular}


The tocilizumab administration and prognosis for each patient are presented in Fig. 1 (a-e). Patient No. 3 died because of COVID-19; her IL-6, FER, and other inflammatory factors were not controlled following treatment with tocilizumab (Fig. 1-c). Further, when her condition deteriorated, her IL-6 levels exceeded the detection limit. Tocilizumab treatment showed good effects in the other four patients, whose IL-6, FER, N/L, and hsCRP levels decreased after tocilizumab administration. All four patients had good oxygen saturation levels and their WBC counts were normal and did not change throughout the whole period of hospitalization.

\section{Changes in lung CT scans}

Patient No. 3 deteriorated and finally died, which was reflected in her lung CT scans. In the other patients, CT scans improved 3-8 days after tocilizumab administration. Lung lesion opacity reduced in the other four patients and became normalized in two patients after 20 and 23 days (Table 3).

Table 3

Changes in lung CT scan after tocilizumab treatment

\begin{tabular}{|c|c|c|c|}
\hline $\begin{array}{l}\text { Patient } \\
\text { No. }\end{array}$ & Lung CT scan & $\begin{array}{l}\text { Days until CT improvement after } \\
\text { tocilizumab }\end{array}$ & $\begin{array}{l}\text { Days until CT } \\
\text { normalized }\end{array}$ \\
\hline 1 & Multiple ground glass shadows in both lungs & 6 & 20 \\
\hline 2 & $\begin{array}{l}\text { Multiple ground glass shadows in both lungs with bilateral } \\
\text { pleural effusion }\end{array}$ & 6 & $N A^{\#}$ \\
\hline 3 & Multiple ground glass shadows in both lungs & Deteriorating & Deteriorating \\
\hline 4 & Multiple ground glass shadows in both lungs & 8 & 23 \\
\hline 5 & Multiple ground glass shadows in both lungs & 3 & $N A^{\#}$ \\
\hline \multicolumn{4}{|c|}{ Abbreviations: CT, computerized tomography; NA, not available. } \\
\hline
\end{tabular}

\subsection{Prognosis in the two patient groups}

As shown in Table 4, the length of hospitalization was greater in the tocilizumab group; however, following tocilizumab treatment, the number of days until lung CT improvement was the same as that in the group who did not receive tocilizumab, and there was no difference in mortality between the groups.

Following tocilizumab administration, no bacterial infection, other viral infections (such as herpes), impaired liver function, hypertension, leukopenia, neutropenia, peripheral edema, allergies, or other adverse reactions were found during the entire hospitalization period.

There was one death in each group, with a total mortality rate of $10.53 \%$.

Table 4

Comparison of prognosis in the two patient groups

\begin{tabular}{|lllll|}
\hline & $\begin{array}{l}\text { No tocilizumab } \\
(\mathbf{n}=\mathbf{1 4})\end{array}$ & $\begin{array}{l}\text { Tocilizumab } \\
(\mathbf{n}=\mathbf{5})\end{array}$ & $\mathbf{t} \mathbf{X}^{2}$ & $\boldsymbol{P}$ \\
\hline Days in hospital & $23.92 \pm 9.98$ & $38.75 \pm 5.19$ & -3.121 & 0.005 \\
\hline Days until CT improved & $8.17 \pm 2.72$ & $5.75 \pm 2.06$ & -1.612 & 0.129 \\
\hline Deaths (n) & 1 & 1 & 0.647 & 0.468 \\
\hline Abbreviation: $\mathrm{CT}$, computerized tomography. & & \\
\hline
\end{tabular}

\section{Discussion}

COVID-19 is more serious and has a higher mortality rate in older adults. The global mortality rate from COVID-19 is $4.84 \%(7)$. A retrospective study of 3,418 black and white patients (mean age, 54 years), reported a mortality rate of $9.36 \%(8)$. In our study of older patients with CRS, the mortality rate was $10.53 \%$, which is higher than the reports cited above; however, age $\geq 65$ years is recognized as a risk factor for mortality from COVID-19(9) and this was the rationale for the focus of our study on these patients.

CRS refers to an over-active, uncontrolled immune response, involving an overwhelming release of proinflammatory mediators. Increased levels of inflammatory cytokines and chemokines, including IL-6, interleukin $1 \beta$, inducible protein 10 , and monocyte chemoattractant protein 1 , may also be a 
cause of fatal complications in patients with COVID-19. In addition to antiviral treatment, IL-6 is the main mediator of CRS toxicity and its levels are related to the severity of CRS induced by chimeric antigen receptor (CAR) T cell therapy $(5,10)$. A systematic review and meta-analysis showed that patients with severe COVID-19 have significantly higher serum IL-6 levels than those with non-severe disease, and that increased mean IL- 6 level was associated with higher patient mortality(11). In the five patients treated with tocilizumab in this study, initial levels of IL-6 were increased by $>10-$ fold compared with normal levels, and were rising at the beginning of the disease. After treatment with tocilizumab, IL-6 levels decreased significantly; however, the IL-6 levels of one patient who died continued to increase significantly, suggesting that IL-6 can be a predictor of prognosis.

Tocilizumab is a humanized recombinant monoclonal anti- IL-6R antibody. It binds to soluble IL-6R and membrane-bound IL-6R to inhibit IL-6 mediated cis- and trans- transcription $(12,13)$. Tocilizumab has been approved by the US Food and Drug Administration for the treatment of severe CAR T cell-induced CRS. After tocilizumab was administered once or twice, $69 \%$ of patients with CAR T cell therapy-induced CRS responded within 14 days, and their fever and hypotension subsided within a few hours, allowing vasopressors to be stopped within a few days(12, 14); however, clinical experience with tocilizumab in treatment for viral disease is very limited and the increased risk of opportunistic infections (including tuberculosis, fungal, or other viral infections) must be taken seriously(15).

A retrospective study of 21 patients with COVID-19 by Xu et al. reported a $75.0 \%$ reduction in oxygen uptake, CT scans showing $90.5 \%$ clearance of lung lesion opacity, and a significant $84.2 \%$ reduction of CRP within 5 days of tocilizumab treatment. No obvious adverse reactions were observed. These data provided evidence that treatment with tocilizumab could immediately improve the symptoms, and was an effective method to reduce mortality, in patients with severe and critical COVID-19(16). Another study involving 15 people showed that tocilizumab treatment could quickly reduce CRP levels in all patients, while IL-6 levels tended to increase first and then decrease. In contrast, untreated patients exhibited a continuous and significant increase in IL-6. Hence, repeat tocilizumab treatment was recommended for critically ill patients with elevated IL-6(17). In our study, we observed that clinical indicators were quickly relieved, and lung CT improved significantly, shortly after administration of tocilizumab to patients with severe COVID-19. These results are similar to those of previous studies, and support the positive therapeutic effects of tocilizumab for patients with severe COVID-19. Further, a systematic review indicated that preliminary investigations of the use of tocilizumab to treat COVID-19 demonstrate benefits, while further studies, such as randomized controlled trials, are needed(18).

The most interesting aspect of this study was the results of comparisons between the two patient groups. We analyzed disease severity and prognosis in all older patients with elevated IL-6 and found that those in the tocilizumab group had more serious disease; however, after the timely application of tocilizumab treatment, the rate of CT improvement and mortality were consistent with those in the group of patients with milder disease. These findings demonstrate that tocilizumab has a positive role in treatment of CRS and is effective against severe COVID-19.

Given the efficacy of tocilizumab in CRS and the key role of IL-6 in COVID-19, Liu et al. suggested that tocilizumab should be considered under the following circumstances. 1) Diagnostic criteria: Early diagnosis of CRS in patients with COVID-19 and rapid instigation of immunomodulatory therapy may be beneficial. 2) Disease severity grading system: Tocilizumab is only suitable for critically ill patients, while the risk-benefit assessment is focused on the symptomatic treatment of patients with mild disease. 3) Combined antiviral treatment: Based on experience with corticosteroids, immunosuppressants may delay viral clearance. Combining immunomodulators with antiviral drugs may be more beneficial(19). In our study, the use of tocilizumab did not cause serious adverse reactions.

\section{Conclusions}

This study was a retrospective cohort study with only a small number of cases. The results support the therapeutic efficacy and safety of tocilizumab for treatment of older adults with severe COVID-19. Randomized controlled trials are required to generate higher level evidence.

\section{List Of Abbreviations}

CAR, chimeric antigen receptor

COVID-19, 2019 novel coronavirus disease

CRS, cytokine release syndrome

$\mathrm{CT}$, computerized tomography

ESR, erythrocyte sedimentation rate

FER, ferritin

hsCRP, high-sensitivity $\mathrm{C}$ reactive protein

IL-6, Interleukin-6

IL-6R, IL-6 receptor 
L, lymphocytes

$\mathrm{N}$, neutrophils

WBC, white blood cells

\section{Declarations}

\section{Ethics approval and consent to participate}

This study was approved by the ethics committee of Beijing Hospital, Beijing, China (2020BJYYEC-097-01). The Ethics Committee agreed to waive informed consent.

\section{Consent for publication}

All participants had consent for publication.

\section{Availability of data and materials}

The datasets used and/or analysed during the current study are available from the corresponding author on reasonable request.

\section{Competing interests}

The authors declare that they have no competing interests.

\section{Funding}

This work was supported by the grant from Beijing Hospital (121-2016008) and Application Research and Achievement Popularization of Clinical Characteristics in Capital (Z151100004015083). The recipient of these fundings was Dr. Mao Yonghui. She was corresponding author who designed the work and substantively revised the manuscript.

\section{Authors' contributions}

MYH designed the work. ZXF, QY and WL took the acquisition of data. LX, LAH, XXM and WXX interpreted data. XLN and ZYW analyzed data. XLN and LX drafted the work and MYH substantively revised it. All authors read and approved the final manuscript.

\section{Acknowledgements}

Not applicable.

\section{References}

1. Chen N, Zhou M, Dong X, Qu J, Gong F, Han Y, et al. Epidemiological and clinical characteristics of 99 cases of 2019 novel coronavirus pneumonia in Wuhan, China: a descriptive study. Lancet (London, England). 2020;395(10223):507-13.

2. Wu C, Chen X, Cai Y, Xia J, Zhou X, Xu S, et al. Risk Factors Associated With Acute Respiratory Distress Syndrome and Death in Patients With Coronavirus Disease 2019 Pneumonia in Wuhan, China. JAMA internal medicine. 2020.

3. Chen G, Wu D, Guo W, Cao Y, Huang D, Wang H, et al. Clinical and immunological features of severe and moderate coronavirus disease 2019. The Journal of clinical investigation. 2020.

4. Ye Q, Wang B, Mao J. The pathogenesis and treatment of the 'Cytokine Storm' in COVID-19. The Journal of infection. 2020;80(6):607-13.

5. Ulhaq ZS, Soraya GV. Interleukin-6 as a potential biomarker of COVID-19 progression. Med Mal Infect. 2020;50(4):382-3.

6. Diagnosis and Treatment Protocol for Novel Coronavirus Pneumonia (Trial Version 7). Chinese medical journal. 2020;133(9):1087-95.

7. Meo SA, Al-Khlaiwi T, Usmani AM, Meo AS, Klonoff DC, Hoang TD. Biological and Epidemiological Trends in the Prevalence and Mortality due to Outbreaks of Novel Coronavirus COVID-19. Journal of King Saud University Science. 2020;32(4):2495-9.

8. Price-Haywood EG, Burton J, Fort D, Seoane L. Hospitalization and Mortality among Black Patients and White Patients with Covid-19. N Engl J Med. 2020;382(26):2534-43.

9. Du RH, Liang LR, Yang CQ, Wang W, Cao TZ, Li M, et al. Predictors of mortality for patients with COVID-19 pneumonia caused by SARS-CoV-2: a prospective cohort study. The European respiratory journal. 2020;55(5).

10. Neelapu SS, Tummala S, Kebriaei P, Wierda W, Gutierrez C, Locke FL, et al. Chimeric antigen receptor T-cell therapy - assessment and management of toxicities. Nature reviews Clinical oncology. 2018;15(1):47-62.

11. Aziz M, Fatima R, Assaly R. Elevated Interleukin-6 and Severe COVID-19: A Meta-Analysis. Journal of medical virology. 2020. 
12. Le RQ, Li L, Yuan W, Shord SS, Nie L, Habtemariam BA, et al. FDA Approval Summary: Tocilizumab for Treatment of Chimeric Antigen Receptor T Cell-Induced Severe or Life-Threatening Cytokine Release Syndrome. The oncologist. 2018;23(8):943-7.

13. Zhang C, Wu Z, Li JW, Zhao H, Wang GQ. The cytokine release syndrome (CRS) of severe COVID-19 and Interleukin-6 receptor (IL-6R) antagonist Tocilizumab may be the key to reduce the mortality. International journal of antimicrobial agents. 2020:105954.

14. Lee DW, Gardner R, Porter DL, Louis CU, Ahmed N, Jensen M, et al. Current concepts in the diagnosis and management of cytokine release syndrome. Blood. 2014;124(2):188-95.

15. Zhao M. Cytokine storm and immunomodulatory therapy in COVID-19: Role of chloroquine and anti-IL-6 monoclonal antibodies. International journal of antimicrobial agents. 2020:105982.

16. Xu X, Han M, Li T, Sun W, Wang D, Fu B, et al. Effective treatment of severe COVID-19 patients with tocilizumab. Proceedings of the National Academy of Sciences of the United States of America. 2020;117(20):10970-5.

17. Luo P, Liu Y, Qiu L, Liu X, Liu D, Li J. Tocilizumab treatment in COVID-19: A single center experience. Journal of medical virology. 2020.

18. Alzghari SK, Acuña VS. Supportive Treatment with Tocilizumab for COVID-19: A Systematic Review. Journal of clinical virology : the official publication of the Pan American Society for Clinical Virology. 2020;127:104380.

19. Liu B, Li M, Zhou Z, Guan X, Xiang Y. Can we use interleukin-6 (IL-6) blockade for coronavirus disease 2019 (COVID-19)-induced cytokine release syndrome (CRS)? Journal of autoimmunity. 2020:102452.

\section{Figures}
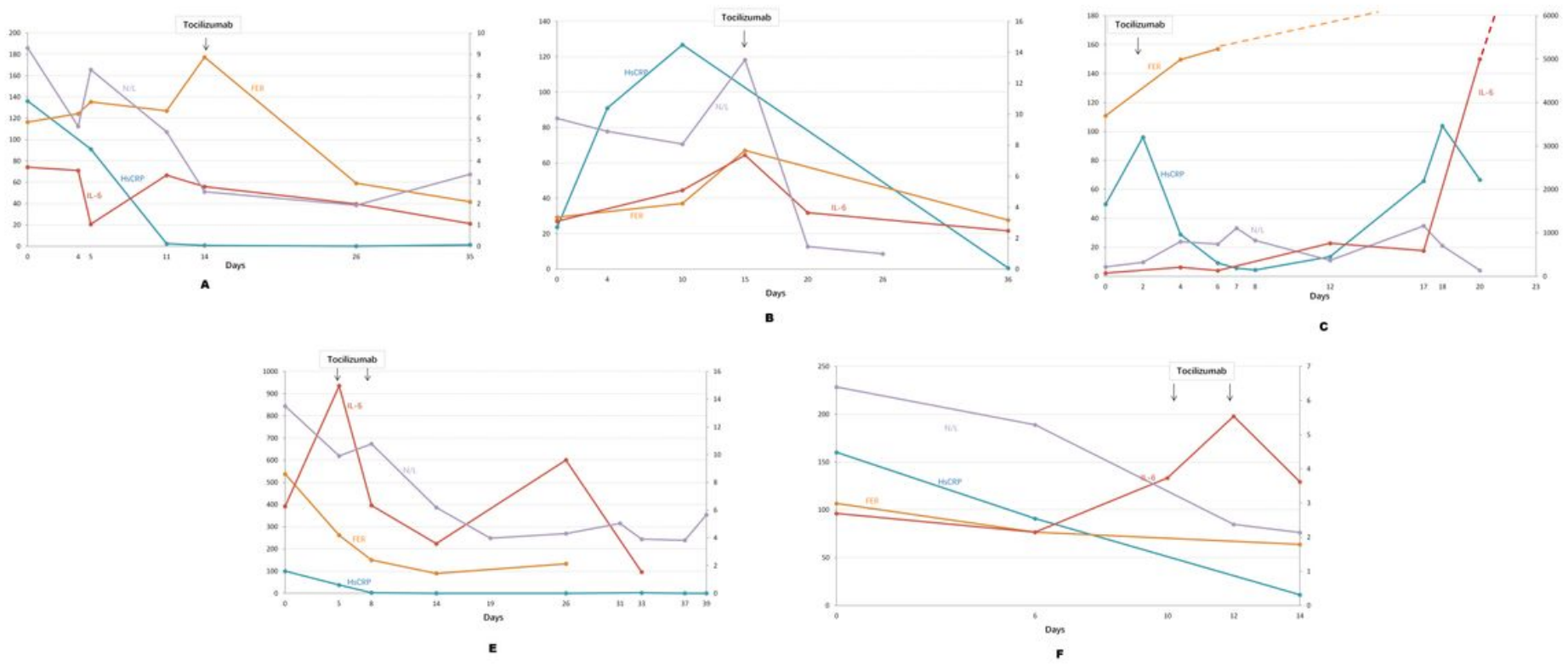

\section{Figure 1}

Disease course in response to tocilizumab in each patient. Panels a to $d$ show data from patient No. 1 to 5 , respectively. The values of each parameter are indicated by lines with different colors, as follows: red, IL-6 (pg/mL); purple, N/L; blue, HsCRP (mg/L); and orange, FER ( $\mu \mathrm{g} / \mathrm{L})$. N/L data is shown on the right $Y$ axis, and the other parameters on the left $Y$ axis. FER: ferritin; HsCRP: high-sensitivity C-reactive protein; IL-6: interleukin-6; N/L: the ratio of neutrophils and lymphocytes. 